\title{
Biosynthetic origin of anthracimycin: a tricyclic macrolide from Streptomyces sp.
}

\author{
Enjuro Harunari ${ }^{1}$, Hisayuki Komaki ${ }^{2}$ and Yasuhiro Igarashi ${ }^{1}$ \\ The Journal of Antibiotics (2016) 69, 403-405; doi:10.1038/ja.2015.118; published online 2 December 2015
}

Anthracimycin (1) is a decalin-fused tricyclic macrolide isolated from terrestrial and marine Streptomyces species (Figure 1). ${ }^{1-3} \mathbf{1}$ shows strong activity against Gram-stain-positive bacteria including Bacillus anthracis and methicillin-resistant Staphylococcus aureus (MRSA). ${ }^{3,4}$ The most intriguing feature of this molecule is its enantiomerism to chlorotonil A (2), a secondary metabolite of a myxobacterium Sorangium cellulosum (Figure 1). ${ }^{5}$ Except for a methyl substitution at $\mathrm{C}-8$ in 2, the absolute configurations of the remaining chiral centers at C-2, C-6, C-7, C-12, C-15 and C-16 are opposite between 1 and 2 although the dichrorination at $\mathrm{C}-4$ in 2 is an additional difference between these compounds. In nature, such enantiomeric natural products can be seen in various organisms from bacteria to plants. ${ }^{6}$ Simple examples include monoterpenes such as $(+)$-limonene and $(-)$-limonene produced from a common linear precursor geranylgeranyl pyrophosphate by the catalysis of (+)-limonene and (-) -limonene synthases, respectively (Figure 2). One of the more complex examples is a fungal alkaloid notoamide. (-)-Notoamide $\mathrm{B}$ is produced by a marine Aspergillus species, whereas its enantiomer (+)-notoamide B is produced by a terrestrial Aspergillus strain. ${ }^{6}$ The enantiomeric biosynthesis of notoamides is proposed to include a common achiral precursor, which is enantiomerically cyclized to a pair of enantiomers through intramolecular Diels-Alder reaction (Figure 2). In these cases, a common single achiral precursor cyclizes into respective enantiomeric products: no chiral centers exist in precursors. Meanwhile, in the biosynthesis of $\mathbf{1}$ and $\mathbf{2}$ it is likely that a pair of chiral precursors independently produced in actinobacterial and myxobacterial cells undergo the intramolecular Diels-Alder reaction (Figure 3). To the best of our knowledge, there exist no such natural products that are generated from a pair of enantiomeric precursors into highly modified structures. In order to understand this unusual enantiomeric biosynthesis, we investigated the biosynthetic origins of $\mathbf{1}$ for further genetic and/or enzymatic analysis. Herein, we describe the results from the ${ }^{13} \mathrm{C}$-labeling experiment of $\mathbf{1}$.

As the carbon skeleton of $\mathbf{1}$ suggested its generation through the malonate pathway, $\left[1,2-{ }^{13} \mathrm{C}_{2}\right]$ acetate was fed to the culture to ensure the alignment of extender units. In the ${ }^{13} \mathrm{C}$ NMR spectrum, split signals arising from the ${ }^{13} \mathrm{C}-{ }^{13} \mathrm{C}$ coupling were clearly observed for all the carbons except for three methyl groups (C-23, C-24 and C-25) and C-11 and C-12 (Supplementary Figure S1). The outer split peaks were invisible owing to the roof effect ${ }^{7}$ caused by the close chemical shifts between C-11 and C-12 ( $\Delta 0.11$ p.p.m.) although these carbons are likely derived from a single acetate unit. In the 2D-INADEQUATE spectrum measured with a parameter set optimized for ${ }^{1} J_{\mathrm{CC}} 45 \mathrm{~Hz}$, cross peaks derived from the intact ${ }^{13} \mathrm{C}_{2}$ acetate units were observed for C-1/C-2, C-3/C-4, C-5/C-6, C-7/C-8, C-9/C-10, C-13/C-14, C-15/ C-16, C-17/C-18, C-19/C-20 and C-21/C-22 (Table 1, Supplementary Figure S3). The INADEQUATE correlation for C-11/C-12 could not be observed owing to the strong coupling also caused by their close chemical shift. The peak separation for C-11 and C-12 was then compared in different solvents and the best separation ( $\Delta 0.31$ p.p.m.) was obtained in benzene- $d_{6}$ (Supplementary Figure S2). The 2D-INADEQUATE spectrum in this solvent, however, still did not give a cross peak for C-11/C-12. It is theoretically predicted that the conventional parameter setting for ${ }^{13} \mathrm{C}-{ }^{13} \mathrm{C}$ coupling detection is not appropriate for carbons with such a small chemical shift difference. ${ }^{8}$ According to this prediction, instead of a normal setting $\tau=1 / 4^{1} J_{\mathrm{CC}}$ for delay, $\tau$ was set to be $3 / 4^{1} J_{\mathrm{CC}}$, which successfully allowed detection of a coupling between C-11 and C-12 (Supplementary Figure S4).

The labeling experiment with the doubly labeled acetate indicated the methyl groups (C-23, C-24, and C-25) were not derived from methylmalonate. To clarify the origin of these methyl carbons, a feeding experiment of a plausible precursor $\mathrm{L}-\left[\right.$ methyl $\left.-{ }^{13} \mathrm{C}\right]$ methionine was carried out. High levels of enrichments of the methyl carbons were observed in the ${ }^{13} \mathrm{C}$ NMR spectrum, confirming that the methyl branching is created by $C$-methylation of the polyketide chain (Table 1, Figure 4, Supplementary Figure S5).

There are three major features that make anthracimycin (1) unusual as an actinomycete metabolite. First, three methyl groups in the polyketide chain of $\mathbf{1}$ are derived from methionine. In polyketide biosynthesis, actinobacteria mostly utilize methylmalonyl CoA for generation of methyl branching in the carbon chain, whereas the fungal polyketide synthase (PKS) exclusively use methionine as a

\footnotetext{
${ }^{1}$ Biotechnology Research Center and Department of Biotechnology, Toyama Prefectural University, Toyama, Japan and ${ }^{2}$ Biological Resource Center, National Institute of Technology and Evaluation (NBRC), Chiba, Japan

Correspondence: Professor Y Igarashi, Biotechnology Research Center and Department of Biotechnology, Toyama Prefectural University, 5180 Kurokawa, Imizu, Toyama 939-0398, Japan.

E-mail: yas@pu-toyama.ac.jp

Received 31 August 2015; revised 8 October 2015; accepted 14 October 2015; published online 2 December 2015
} 
substrate for $C$-methylation to create methyl branching. ${ }^{9}$ It is uncommon for actinobacteria to generate the methyl substitution in the polyketide chain by $C$-methylation in type I polyketides. Examples are limited to several secondary metabolites: aplasmomycin, ${ }^{10}$ boromycin, ${ }^{11}$ aurodox ${ }^{12}$ and lankacidin C. ${ }^{13}$ Second, anthracimycin (1) has the same carbon framework as a myxobacterial metabolite chlorotonil A (2) except for an extra methyl substitution and halogenation modification. Actinobacteria and myxobacteria are phylogenetically distinct: the former are Gram-stain-positive and the latter are Gram-stain-negative. It is known that distantly related microbes can engage in horizontal transfer of secondary metabolite biosynthetic genes. However, it is very rare that actinomycetes and myxobacteria are producing secondary metabolites that share a common carbon framework. One such example only includes actinofuranones from Streptomyces and aurafurones from a Stigmastella strain although the structural similarity is lower than the case of $\mathbf{1}$ and $2 .{ }^{14}$ Third, anthracimycin (1) and chlorotonil A (2) have the opposite absolute configuration. There is no other example of enantiomeric compounds with polycyclic, complex structures among the type I PKS-derived secondary metabolites.

Recently, we reported the draft genome sequencing of the producing strain Streptomyces sp. TP-A0875. ${ }^{15}$ Two type I PKS gene clusters exist in the genome and one of them is assigned to the biosynthetic gene cluster of $\mathbf{1}$ on the basis of PKS gene function prediction. Future

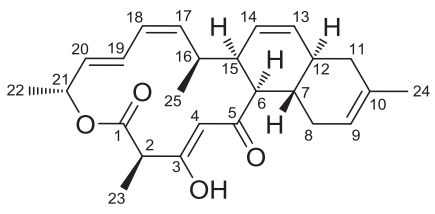

anthracimycin (1)

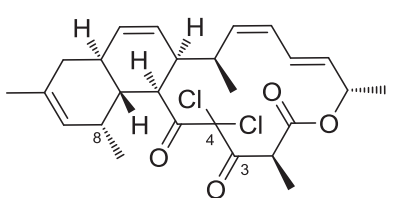

chlorotonil A (2)

Figure 1 Structures of anthracimycin (1) and chlorotonil A (2).

work will be directed toward biochemical analysis to elucidate the molecular basis of enantiomeric biosynthesis.

\section{GENERAL PROCEDURE}

Sodium $\left[1,2-{ }^{13} \mathrm{C}_{2}\right]$ acetate was purchased from Cambridge Isotope Laboratories (Tewksbury, MA, USA), Inc. L- $\left[\right.$ Methyl- $\left.{ }^{13} \mathrm{C}\right]$ methionine was purchased from ISOTEC Inc. (Miamisburg, OH, USA). NMR spectra were obtained on a Bruker AVANCE 500 spectrometer (Bruker BioSpin KK Kanagawa, Japan) in $\mathrm{CDCl}_{3}$ and benzene- $d_{6} .{ }^{13} \mathrm{C}$ chemical shifts were referenced to the residual solvent signals $\left(\mathrm{CDCl}_{3}: \delta_{\mathrm{C}} 77.0\right.$; benzene- $\left.d_{6}: \delta_{\mathrm{C}} 127.7\right)$.

\section{Microorganism}

Streptomyces sp. strain TP-A0875 was isolated from compost material collected in Ishikawa, Japan. The strain was identified as a member of the genus Streptomyces on the basis of $99.4 \% \quad 16 \mathrm{~S}$ rRNA gene sequence identity (1453 nucleotides; DDBJ accession number AB451554) with Streptomyces collinus NBRC $12759^{\mathrm{T}}$ (accession number AB184123).

\section{FERMENTATION}

Strain TP-A0875 growing on a plate culture was inoculated into a $500-\mathrm{ml} \mathrm{K}-1$ flask containing $100 \mathrm{ml}$ of the V-22 seed medium consisting of soluble starch $1.0 \%$, glucose $0.5 \%$, NZ-case $0.3 \%$, yeast extract, $0.2 \%$, Tryptone (Difco Laboratories, Detroit, MI, USA) $0.5 \%$, $\mathrm{K}_{2} \mathrm{HPO}_{4} 0.1 \%, \mathrm{MgSO}_{4} \cdot 7 \mathrm{H}_{2} \mathrm{O} 0.05 \%$ and $\mathrm{CaCO}_{3} 0.3 \%(\mathrm{pH} 7.0)$. The flask was placed on a rotary shaker $\left(200\right.$ r.p.m.) at $30{ }^{\circ} \mathrm{C}$ for 4 days. Then, the seed culture $(3 \mathrm{ml})$ was transferred into $500-\mathrm{ml} \mathrm{K}-1$ flasks each containing $100 \mathrm{ml}$ of the $\mathrm{A}-3 \mathrm{M}$ production medium consisting of soluble starch $2.0 \%$, glycerol $2.0 \%$, glucose $0.5 \%$, Pharmamedia (Traders Protein, Memphis, TN, USA) $1.5 \%$, yeast extract $0.3 \%$ and Diaion HP-20 resin (Mitsubishi Chemical Co., Kanagawa, Japan) 1\%. The $\mathrm{pH}$ of the medium was adjusted to 7.0 before sterilization. The inoculated flasks were placed on a rotary shaker $\left(200\right.$ r.p.m.) at $30^{\circ} \mathrm{C}$ for 6 days.<smiles>C=C(C)C1CC=C(C)CC1</smiles>

$(-)-(S)-$ limonene

$(+)-(R)$-limonene

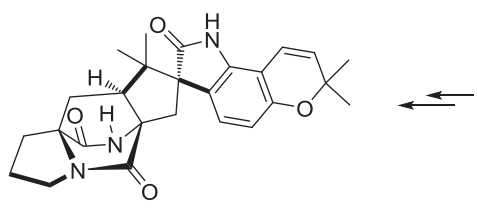

(-)-notoamide B
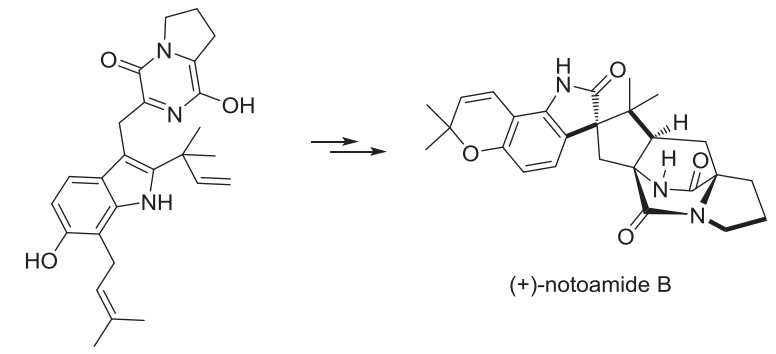

(+)-notoamide B

Figure 2 Enantiomeric natural products from achiral precursors.

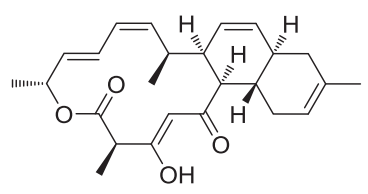

anthracimycin (1)

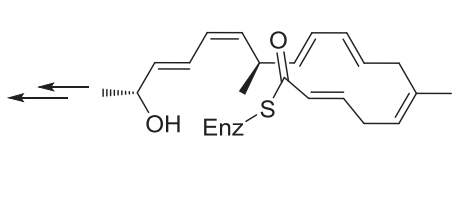

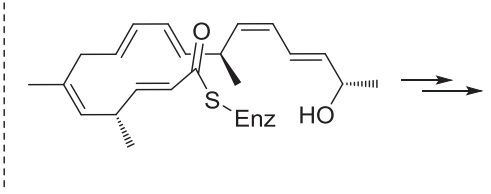

Figure 3 Plausible biogenesis of anthracimycin (1) and chlorotonil A (2) from chiral precursors. 
Table 1 Incorporation of ${ }^{13} \mathrm{C}$-labeled precursors into 1

\begin{tabular}{|c|c|c|c|c|c|}
\hline \multirow[b]{2}{*}{ Positiona } & \multicolumn{3}{|c|}{$\left[1,2-{ }^{13} C_{2}\right]$ acetate (benzene- $d_{6}$ ) } & \multicolumn{2}{|c|}{$\begin{array}{l}L-\left[\text { methyl- }{ }^{13} \mathrm{C}\right] \text { methionine } \\
\qquad\left(\mathrm{CDCl}_{3}\right)\end{array}$} \\
\hline & $\delta_{C}$ & ${ }^{1} J_{C C}(H z)$ & 2D-INADEQUATE & $\delta_{C}$ & Relative enrichment ${ }^{b}$ \\
\hline 1 & 168.1 & 53 & 2 & 168.7 & 0.74 \\
\hline 2 & 48.9 & 53 & 1 & 49.1 & 0.94 \\
\hline 3 & 190.4 & 63 & 4 & 190.7 & 0.66 \\
\hline 4 & 102.8 & 63 & 3 & 102.9 & 0.88 \\
\hline 5 & 194.0 & 45 & 6 & 194.0 & 0.75 \\
\hline 6 & 52.5 & 45 & 5 & 52.5 & 0.94 \\
\hline 7 & 32.9 & 35 & 8 & 32.9 & 0.90 \\
\hline 8 & 31.3 & 35 & 7 & 31.2 & 0.93 \\
\hline 9 & 121.2 & 33 & 10 & 120.9 & 0.91 \\
\hline 10 & 133.2 & 33 & 9 & 133.8 & 0.64 \\
\hline 11 & 37.5 & 73 & 12 & 37.4 & 0.97 \\
\hline 12 & 37.2 & 73 & 11 & 37.3 & 1.05 \\
\hline 13 & 132.8 & 69 & 14 & 132.9 & 0.97 \\
\hline 14 & 124.9 & 69 & 13 & 124.8 & 0.99 \\
\hline 15 & 45.9 & 32 & 16 & 45.9 & 0.93 \\
\hline 16 & 32.7 & 32 & 15 & 32.7 & 0.92 \\
\hline 17 & 138.6 & 68 & 18 & 138.9 & 0.82 \\
\hline 18 & 126.3 & 68 & 17 & 125.9 & 1.01 \\
\hline 19 & 123.6 & 73 & 20 & 123.6 & 0.78 \\
\hline 20 & 131.7 & 73 & 19 & 131.5 & 0.90 \\
\hline 21 & 69.4 & 39 & 22 & 69.8 & 0.83 \\
\hline 22 & 20.4 & 39 & 21 & 20.8 & 1.00 \\
\hline 23 & 11.6 & & & 11.7 & 19.75 \\
\hline 24 & 23.2 & & & 23.4 & 20.21 \\
\hline 25 & 16.3 & & & 16.3 & 20.75 \\
\hline
\end{tabular}

aThree carbons C-7, C-11, and C-12 are missassigned in the previous report. ${ }^{3}$ Carbon chemical shifts were corrected to be 37.4 p.p.m. for C-11, 37.5 p.p.m. for C-12, and 33.0 p.p.m. for shifts were corrected to be 37.4 p.p.m. for $\mathrm{C}-11,37.5$ p.p.m. for $\mathrm{C}-12$, and $33.0 \mathrm{C}$. ${ }^{13} \mathrm{C}-{ }^{13} \mathrm{C}$ coupling constants and 2D-INADEQUATE analysis. $\mathrm{C}-7$ on the basis of ${ }^{13} \mathrm{C}-{ }^{13} \mathrm{C}$ coupling constants and $2 \mathrm{D}-$-INADEQUATE analysis.
${ }^{\mathrm{b} 13} \mathrm{C}$ signal intensity of each peak in the labeled $\mathbf{1}$ divided by that of the corresponding signal in the unlabeled $\mathbf{1}$, respectively, normalized to give an enrichment ratio of 1 for the unenriched $\mathrm{C}$-22 methyl peak. The numbers in bold type indicate ${ }^{13} \mathrm{C}$-enriched atoms from ${ }^{13} \mathrm{C}$-labeled precursors.

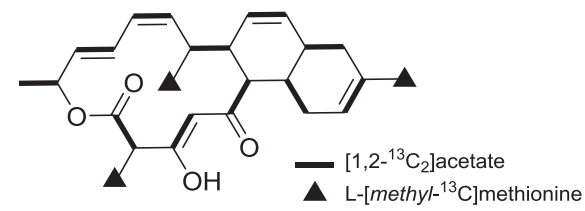

Figure $4{ }^{13} \mathrm{C}$-labeling pattern of anthracimycin (1).

\section{EXTRACTION AND ISOLATION}

After incubation, $100 \mathrm{ml}$ of 1-butanol was added to each flask, and the flasks were allowed to shake for an hour. The mixture was centrifuged at 6000 r.p.m. for $10 \mathrm{~min}$ and the organic layer was separated from the aqueous layer. The solvent was removed by evaporation to give $2.0 \mathrm{~g}$ of a crude extract from $1 \mathrm{l}$ of culture. This crude extract was fractionated using silica gel column chromatography with a step gradient of $\mathrm{CHCl}_{3}-\mathrm{MeOH}(1: 0,20: 1,10: 1,4: 1,2: 1,1: 1$, and 0:1 v/v). Fraction 3 (10:1) containing 1 was concentrated to give $81 \mathrm{mg}$ of pale yellow oil, which was further fractionated by reversed-phase ODS column chromatography with a step gradient of $\mathrm{MeCN} / 0.1 \% \quad \mathrm{HCO}_{2} \mathrm{H}$ $(5: 5,6: 4,7: 3,8: 2,9: 2$, and 10:0 v/v). The fraction eluted with $90 \%$ $\mathrm{MeCN}$ was pooled and evaporated in vacuo, and the major part of the solvent was evaporated in vacuo. The remaining aqueous solution was extracted twice with EtOAc to give colorless oil $(8.1 \mathrm{mg})$. The final purification was achieved by preparative HPLC (Cosmosil 5C18-ARII, $\left.10 \times 250 \mathrm{~mm}, 4 \mathrm{ml} \mathrm{min}^{-1}\right)$ using a gradient of $\mathrm{MeCN} / 0.1 \%$ $\mathrm{HCO}_{2} \mathrm{H}$ (MeCN concentration: $80-100-100 \%$ for $0-10-20 \mathrm{~min}$ ) at $4 \mathrm{ml} \mathrm{min}{ }^{-1}$, yielding $1(5.6 \mathrm{mg})$ with a retention time of $13.3 \mathrm{~min}$.

\section{INCORPORATION OF ${ }^{13} \mathrm{C}$-LABELED PRECURSORS}

Feeding experiments were performed using $\left[1,2-{ }^{13} \mathrm{C}_{2}\right]$ acetate and $\mathrm{L}-\left[\right.$ methyl $\left.-{ }^{13} \mathrm{C}\right]$ methionine. The incubation, cultivation and purification were performed in the same manner as described above. Addition of ${ }^{13} \mathrm{C}$-labeled precursors ( $1 \mathrm{ml}$ solution per flask) was initiated at $48 \mathrm{~h}$ after inoculation and periodically carried out every $24 \mathrm{~h}$ for four times. After further incubation for $24 \mathrm{~h}$ the cultures were extracted with 1- butanol.

1. Sodium $\left[1,2-{ }^{13} \mathrm{C}_{2}\right]$ acetate: After feeding of sodium $\left[1,2-{ }^{13} \mathrm{C}_{2}\right]$ acetate (total $800 \mathrm{mg} ; 20 \mathrm{mg} \times 10$ flasks $\times 4$ days), $5.6 \mathrm{mg}$ of ${ }^{13} \mathrm{C}$-labeled 1 was obtained from $1 \mathrm{l}$ of culture as described above.

2. $\mathrm{L}-\left[\right.$ Methyl $\left.-{ }^{13} \mathrm{C}\right]$ methionine: After feeding of $\mathrm{L}-\left[\right.$ methyl $\left.-{ }^{13} \mathrm{C}\right]$ methionine (total $100 \mathrm{mg} ; 2.5 \mathrm{mg} \times 10$ flasks $\times 4$ days), $3.6 \mathrm{mg}$ of ${ }^{13} \mathrm{C}$-labeled 1 was obtained from 11 of culture.

\section{CONFLICT OF INTEREST}

The authors declare no conflict of interest.

\section{ACKNOWLEDGEMENTS}

We are grateful to Dr Eri Fukushi of Hokkaido University for excellent advices on 2D-INADEQUATE measurements. This work was supported by a Grant-inaid for Scientific Research from the Ministry of Education, Culture, Sports, and Technology of Japan to Y.I., the Japan Society for the Promotion of Science (JSPS) for Young Scientists (15K18692) to EH and Institute for Fermentation, Osaka (IFO) for Young Scientists to EH.

1 Igarashi, Y., lida, T., Miyanouchi, K. \& Sudo, Y. Production of TPU0114. PCT/JP 2011/010586

2 Kim, Y., In, Y., Ishida, T., Onaka, H. \& Igarashi, Y. Biosynthetically unique polyketides from Streptomyces sp. Organ. Comm. 54th Symp. Chem. Nat. Prod. 18 (2012).

3 Jang, K. H. et al. Anthracimycin, a potent anthrax antibiotic from a marine-derived actinomycete. Angew. Chem. Int. Ed. 52, 7822-7824 (2013).

4 Hensler, M. E. et al. Anthracimycin activity against contemporary methicillin-resistant Staphylococcus aureus. J. Antibiot. 67, 549-553 (2014).

5 Gerth, K., Steinmetz, H., Höfle, G. \& Jansen, R. Chlorotonil A, a macrolide with a unique gem-dichloro-1,3-dione functionality from Sorangium cellulosum, so ce1525. Angew. Chem Int. Ed. 47, 600-602 (2008).

6 Finefield, J. M., Sherman, D. H., Kreitman, M. \& Williams, R. M. Enantiomeric natural products: Occurrence and biogenesis. Angew. Chem. Int. Ed. 51, 4802-4836 (2012).

7 Hore, P. Nuclear magnetic resonance. 2nd edn 34-37 (Oxford University Press, Oxford, UK, 2015).

8 Bax, A. \& Freeman, R. Investigation of ${ }^{13} \mathrm{C}-{ }^{13} \mathrm{C}$ couplings in natural abundance samples: The strong coupling case. J. Magn. Reson. 41, 507-511 (1980).

9 Dewick, P. M. Medicinal Natural Products: A Biosynthetic Approach. 3rd edn (Wiley \& Sons, Hoboken, NJ, USA, 2009).

10 Chen, T. S., Chang, C. J. \& Floss, H. G. Biosynthesis of the boron-containing macrolide antibiotic aplasmomycin by Streptomyces griseus. J. Am. Chem. Soc. 103, 4565-4568 (1981).

11 Chen, T. S., Chang, C. J. \& Floss, H. G. On the biosynthesis of boromycin. J. Org. Chem. 46, 2661-2666 (1981).

12 Liu, C.-M., Williams, T. H. W. \& Pitcher, R. G. P. ${ }^{13}$ C-NMR studies on the biosynthesis of aurodox (antibiotic X-5108). J. Antibiot. 32, 414-417 (1979).

13 Kakinuma, K., Uzawa, J. \& Uramoto, M. Biosynthesis of the 17-membered carbocyclic ring of lankacidin antibiotics. Tetrahedr. Lett. 23, 5303-5306 (1982).

14 Kunze, B., Reichenbach, H., Müller, R. \& Höfle, G. Aurafuron A and B, new bioactive polyketides from Stigmatella aurantiaca and Archangium gephyra (Myxobacteria). Fermentation, isolation, physico-chemical properties, structure and biological activity. J. Antibiot. 58, 244-251 (2005).

15 Komaki, H. et al. Draft genome sequence of an anthracimycin-producer, Streptomyces sp. TP-A0875. Genome Announc. 3, e01149-15 (2015).

Supplementary Information accompanies the paper on The Journal of Antibiotics website (http://www.nature.com/ja) 